\title{
Hypertension and type 2 diabetes: What family physicians can do to improve control of blood pressure - an observational study
}

Wayne Putnam ${ }^{*}$, Beverley Lawson ${ }^{1}$, Farokh Buhariwalla², Mary Goodfellow², Rose Anne Goodine², Jennifer Hall², Kendrick Lacey ${ }^{2}$, lan MacDonald ${ }^{2}$, Frederick I Burge ${ }^{1}$, Nandini Natarajan ${ }^{1}$, Ingrid Sketris ${ }^{3}$, Beth Mann ${ }^{4}$, Peggy Dunbar ${ }^{5}$, Kristine Van Aarsen ${ }^{1}$ and Marshall S Godwin ${ }^{6}$

\begin{abstract}
Background: The prevalence of type 2 diabetes is rising, and most of these patients also have hypertension, substantially increasing the risk of cardiovascular morbidity and mortality. The majority of these patients do not reach target blood pressure levels for a wide variety of reasons. When a literature review provided no clear focus for action when patients are not at target, we initiated a study to identify characteristics of patients and providers associated with achieving target BP levels in community-based practice.

Methods: We conducted a practice- based, cross-sectional observational and mailed survey study. The setting was the practices of 27 family physicians and nurse practitioners in 3 eastern provinces in Canada. The participants were all patients with type 2 diabetes who could understand English, were able to give consent, and would be available for follow-up for more than one year. Data were collected from each patient's medical record and from each patient and physician/nurse practitioner by mailed survey. Our main outcome measures were overall blood pressure at target $(<130 / 80)$, systolic blood pressure at target, and diastolic blood pressure at target. Analysis included initial descriptive statistics, logistic regression models, and multivariate regression using hierarchical nonlinear modeling (HNLM).
\end{abstract}

Results: Fifty-four percent were at target for both systolic and diastolic pressures. Sixty-two percent were at systolic target, and $79 \%$ were at diastolic target. Patients who reported eating food low in salt had higher odds of reaching target blood pressure. Similarly, patients reporting low adherence to their medication regimen had lower odds of reaching target blood pressure.

Conclusions: When primary care health professionals are dealing with blood pressures above target in a patient with type 2 diabetes, they should pay particular attention to two factors. They should inquire about dietary salt intake, strongly emphasize the importance of reduction, and refer for detailed counseling if necessary. Similarly, they should inquire about adherence to the medication regimen, and employ a variety of patient-oriented strategies to improve adherence.

\section{Background}

The age-standardized prevalence of type 2 diabetes in Canada rose by a relative $21 \%$ from 2003 to 2007 to $6.2 \%$ overall [1]. Most of these patients with diabetes also have hypertension, a modifiable risk factor for heart

\footnotetext{
* Correspondence: wayne.putnam@dal.ca

'Department of Family Medicine, Dalhousie University, Oxford St., Halifax, NS, B3H 4R2, Canada

Full list of author information is available at the end of the article
}

disease. In a baseline phase preceding this study, $78.7 \%$ of type 2 diabetes patients in family practices in the Maritime Provinces had been diagnosed with hypertension [2], using routine office sphygmomanometers. This is higher than one other comparable Canadian study (63\%) [3], but similar to a second (75.8\%) [4]. As comorbidities, hypertension and diabetes substantially increase the risk of cardiovascular morbidity and mortality [5].

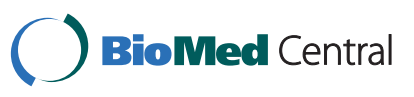

() 2011 Putnam et al; licensee BioMed Central Ltd. This is an Open Access article distributed under the terms of the Creative Commons Attribution License (http://creativecommons.org/licenses/by/2.0), which permits unrestricted use, distribution, and reproduction in any medium, provided the original work is properly cited. 
Although effective treatments exist for hypertension, most patients with type 2 diabetes do not reach target blood pressures. In the earlier baseline phase, only $27.1 \%$ of patients were at target $(<130 / 80)$ [2], within the range of $13-36 \%$ reported at target in other studies in community settings [6-10].

A review of the literature revealed a wide array of patient, physician, and health system factors contributing to the success or failure in reaching target BP goals. Many, such as patient age [4,11-17] and sex $[4,11,13,16,18-20]$ and physician age [12] and sex [12,14] are not modifiable. Health system factors such as access to drug insurance plans have been cited by physicians as a major facilitator of care of patients with diabetes [21], but that too is not amenable to action on the part of the individual physician. Among the most frequently cited reasons for poor control of blood pressure in hypertensive patients is a lack of adequate drug treatment, with calls for a more aggressive approach [22,23]. Our baseline data had shown that patients were already taking an average of 2.5 antihypertensive medications [2], close to the 2.9 found necessary to reach a target of less than 130/80 in an American study [18].

The literature review provided no clear guidance to our team of eight community family physicians that had collected the baseline phase data regarding where to focus their attention when patients are not at target blood pressures. With the support of university colleagues, they initiated a study to identify characteristics of patients and providers associated with achieving target BP levels in patients with type 2 diabetes in typical community-based practice. This paper will outline which characteristics were found to be significant and provide suggestions for increased attention in office practice.

\section{Methods}

This practice-based, cross-sectional study which included both observational and mailed survey components was conducted in family physician and nurse practitioner practices in the Maritime Family Practice Research Network in 3 eastern provinces in Canada. The study was first approved by our institutional Research Ethics Board (CD-2004-221); it was subsequently approved by six more Research Ethics Boards with jurisdiction over participating practices. Data for this phase of our study was collected between January 2008 and June 2010. All participants signed informed consent forms.

\section{Subjects}

Potential participants included all patients of each practice with diagnoses of type 2 diabetes and hypertension who could understand English, were able to give consent, and were expected to be available for follow-up for more than one year. Patients were included if they had their most recent $\mathrm{BP}$ measurement taken with a BpTRUTM within the past six months in order to relate that pressure with the results of the patient survey. Because antihypertensive drug prescribing was one of our study variables, only patients taking those medications were included in the analysis.

\section{Data sources and measures}

Data was obtained from three sources: the patient's medical record, a self-administered survey mailed to each patient and a survey completed by each participating provider. Measures (potential predictor and outcome variables) from all sources were guided by a modification of the Andersen conceptual model of health service utilization [24] and included a variety of individual patient (population) characteristics and contextual system and provider factors (Table 1).

Clinical data relevant to the diagnosis and management of type 2 diabetes and hypertension were extracted from each patient's medical record. Individual level patient characteristics included predisposing characteristics (age, gender) and factors associated with the identification of evaluated need such as the durations of diabetes and hypertension, targeted clinical factors (HbA1C equal to or less than 7.0\%, LDL-CHOL $<2.5$ $\mathrm{mmol} / \mathrm{L}$, and Total CHOL:HDL-CHOL ratio < 4.0) [25], renal status, and a co-morbidity index. Health service use from the medical record was represented by the intensity of antihypertensive drug prescribing. For each patient, details pertaining to all prescribed antihypertensive medications currently being taken at the time of BP recording were extracted. Antihypertensive drug classes included in the CHEP recommendations [26,27] were then used in the calculation of prescribing drug "intensity" through the adaptation of an approach first described by Menard et al. [28]. Briefly, for each patient, the total daily dose prescribed for each antihypertensive medication was divided by the upper limit of the range of doses usually effective for hypertension as listed in the 2006 Compendium of Pharmaceuticals and Specialties [29]. The sum of "intensity" scores for each drug was then calculated.

The main outcomes of interest, or evaluated health status, were overall BP at target, systolic blood pressure (SBP) at target and diastolic blood pressure (DBP) at target. BP readings extracted from the patient medical record were the most recent measures taken with an automated oscillometric machine (BpTRUTM). The BpTRU ${ }^{\mathrm{TM}}$ readings were done according to a protocol provided with the machine, using the average of the second through fifth readings. Blood pressure at target was defined as less than $130 / 80 \mathrm{mmHg}$, consistent with the CHEP recommendations [26,27]. Details of clinical data 
Table 1 Andersen's Conceptual Model of Health Service Utilization adapted to investigate BP outcome

\begin{tabular}{|c|c|c|c|c|c|c|}
\hline \multicolumn{2}{|c|}{ ENVIRONMENT $\rightarrow$} & \multicolumn{3}{|c|}{ POPULATION CHARACTERISTICS $\rightarrow$} & \multirow{2}{*}{$\begin{array}{l}\text { HEALTH BEHAVIOUR } \rightarrow \\
\text { Use of Health Services }\end{array}$} & \multirow{2}{*}{$\begin{array}{l}\text { OUTCOMES } \\
\begin{array}{l}\text { Evaluated health } \\
\text { status }\end{array}\end{array}$} \\
\hline & $\begin{array}{l}\text { Health } \\
\text { care } \\
\text { system }\end{array}$ & $\begin{array}{l}\text { Predisposing } \\
\text { characteristics }\end{array}$ & $\begin{array}{l}\text { Enabling } \\
\text { Resources }\end{array}$ & Need & & \\
\hline $\begin{array}{l}\text { Level } 1 \\
\text { Individual } \\
\text { Patient } \\
\text { factors }\end{array}$ & & $\begin{array}{l}\text { Demographics } \\
\text {-Age } \\
\text {-Gender } \\
\text {-Ethnicity } \\
\text { Social Structure } \\
\text {-Education } \\
\text {-Marital status }\end{array}$ & $\begin{array}{l}\text { Personal/family } \\
\text {-Private drug } \\
\text { insurance }\end{array}$ & $\begin{array}{l}\text { Evaluated need } \\
\text {-Duration of } \\
\text { hypertension } \\
\text {-Duration of } \\
\text { diabetes } \\
\text {-Body mass } \\
\text { index } \\
\text {-HbA1C } \\
\text {-HDL } \\
\text {-LDL } \\
\text {-Renal Status } \\
\text {-Co-morbidity } \\
\text { Perceived need } \\
\text {-Bayliss' Comorbidity } \\
\text { Index }\end{array}$ & $\begin{array}{l}\text { Antihypertensive drug } \\
\text { intensity } \\
\text { Health care system } \\
\text {-Diabetes } \\
\text { Education } \\
\text { Attendance } \\
\text { Personal health practices } \\
\text {-Medication } \\
\text { Adherence } \\
\text { (Morisky score) } \\
\text {-Blood Pressure } \\
\text { Self-Monitoring } \\
\text {-Smoking } \\
\text {-Physical activity } \\
\text {-Diet } \\
\text {-Alcohol } \\
\text { Consumption }\end{array}$ & $\begin{array}{l}\text { Measured blood } \\
\text { pressure }(\mathrm{BP}) \\
\text {-Overall BP at target } \\
\text {-Systolic BP at target } \\
\text {-Diastolic BP at target }\end{array}$ \\
\hline $\begin{array}{l}\text { Level } 2 \\
\text { Contextual } \\
\text { Physician/ } \\
\text { Practice/ } \\
\text { factors }\end{array}$ & Province & & $\begin{array}{l}\text { Provider } \\
\text { Characteristics } \\
\text {-Gender } \\
\text {-Years in Family } \\
\text { Medicine } \\
\text {-Payment type } \\
\text {-Practice type } \\
\text {-Practice nurse } \\
\text { (Y/N) } \\
\text {-Urban/Rural }\end{array}$ & & & \\
\hline
\end{tabular}

extracted may be found in an earlier paper reporting the first phase of the study [2].

Information pertaining to patients not normally found in the medical record was obtained directly from them using a survey questionnaire developed for this study. Survey administration was by mail and followed a modified Dillman's method [30]. Each eligible patient was mailed an initial package containing a personalized letter of invitation, information about the study, the questionnaire and a post-paid return envelope. A follow-up reminder was sent to all who had not responded within five weeks after the initial invitation. Survey materials sent to patients were mailed from their provider's office. The patient survey solicited information regarding additional patient characteristics (predisposing characteristics, enabling resources, perceived need) and health behaviours (use of health services, personal health practices) (Table 1). To aid in the capture of some of this information, two validated, reliable scales were included: the Morisky Medication Adherence Scale, a four-item self-report adherence measure to evaluate medication adherence in hypertensive patients [31], and a comorbidity assessment instrument developed by E. A. Bayliss to estimate the number of comorbid conditions and patient's perceived disease burden from these conditions (a "comorbidity index") [32].
To account for clustering of patients within provider practices across the three provinces, contextual information pertaining to the practice and the system they operate within were collected through a survey mailed to each participating provider using the same method as that for the patient survey. Items in this provider survey solicited responses regarding provider demographics and practice information.

\section{Analysis}

Following initial descriptive statistics, bivariate regression models were used to evaluate the crude association between each potential predictor variable and all outcomes of interest. This was followed by multivariate analysis where hierarchical nonlinear modeling (HNLM) was utilized in order to account for the clustering of patients associated with a provider. Predictors found to be significant at $p \leq 0.2$ in the bivariate analyses were considered for inclusion in the hierarchical multivariate modeling. For the hierarchical analyses, all predictors were tested for random or fixed slopes and accounted for in the regression equations as required.

A manual stepwise procedure was used for the addition of individual predictors to build the model. Individual level patient predictors (Level 1) were tested first, followed by contextual system and provider predictors 
(Level 2). Predictors were considered statistically significant in the final model with a $\mathrm{p}$-value $\leq 0.05$.

HLM version 6.03 [33] was used for HNLM analyses. SAS version 9.1 [34] was used for all other analyses.

\section{Results}

In total, 656 patients met the inclusion criterion of this study and were asked to complete the self-administered survey. Of these eligible patients, 588 completed the patient survey for a response rate of $89.6 \%$. Eighteen respondents were removed from analyses due to missing critical information, such as incomplete survey information from their provider or antihypertensive medications not being prescribed. This resulted in a final cohort of 570 for analysis. These 570 patients had been recruited by 27 providers who represented a diverse group of family physicians $(\mathrm{n}=25)$ and nurse practitioners $(\mathrm{n}=$ 2) from urban and rural settings, and various practice types and payment methods (Table 2 ). Only 11 or $1.9 \%$ of patients were associated with a nurse practitioner practice. Most patients (67.2\%) came from practices in which virtually all eligible patients had been approached for participation. There were no statistically significant differences between patients in all practices for age, gender, blood pressure at target or antihypertensive drug intensity score.

Individual patient characteristics are summarized in Table 3. Overall 54.4\% were at target for overall BP (both SBP and DBP), 62.1\% were at SBP target, and $79.3 \%$ were at DBP target.

Table 4 summarizes the results of the final multivariate analysis and shows a variety of statistically significant predictors of reaching target pressures. No predisposing or personal/family patient characteristics were significantly associated with attaining overall target BP. Two evaluated need characteristics (duration of diagnosis of hypertension, renal status) and three personal health practices (salt intake, medication adherence, BP self-monitoring) were significantly associated. Compared to patients diagnosed with hypertension over the past five years, those with a five to ten year duration of diagnosis of hypertension had greater chance of reaching overall targeted BP (adjusted odd ratio $[\mathrm{AOR}]=1.62 ; 95 \%$ confidence interval $[\mathrm{CI}]=$ 1.07-2.44). Lower odds of reaching target BP was associated with patients diagnosed with overt nephropathy compared to those with a normal renal status (AOR $=$

Table 2 Contextual System and Provider Characteristics $(\mathbf{n}=\mathbf{2 7}$ )

\begin{tabular}{|c|c|c|}
\hline CATEGORICAL VARIABLES & Physician Frequency (\%) & Overall Number of Patients (\%) \\
\hline \multicolumn{3}{|l|}{ System Characteristics } \\
\hline \multicolumn{3}{|l|}{ PROVINCE } \\
\hline New Brunswick & $10(37.04)$ & $191(33.51)$ \\
\hline Nova Scotia & $16(59.26)$ & $348(61.05)$ \\
\hline Prince Edward Island & $1(3.70)$ & $31(5.44)$ \\
\hline \multicolumn{3}{|l|}{ Provider Characteristics } \\
\hline \multicolumn{3}{|l|}{ GENDER } \\
\hline Male & $13(48.15)$ & $415(72.81)$ \\
\hline Female & $14(51.85)$ & $155(27.19)$ \\
\hline MEAN YEARS IN PRACTICE (SD) & $20.37(10.52)$ & -———————————— \\
\hline \multicolumn{3}{|l|}{ PROVIDER TYPE } \\
\hline Family Physician & $25(92.59)$ & 559 (98.07) \\
\hline Nurse Practitioner & $2(7.41)$ & $11(1.93)$ \\
\hline \multicolumn{3}{|l|}{ PRACTICE SETTING } \\
\hline Urban & $16(59.26)$ & $303(53.16)$ \\
\hline Rural & $11(40.74)$ & $267(46.84)$ \\
\hline \multicolumn{3}{|l|}{ PAYMENT TYPE } \\
\hline Fee for Service & $12(44.44)$ & $415(72.81)$ \\
\hline Other & $15(55.56)$ & $155(27.19)$ \\
\hline \multicolumn{3}{|l|}{ PRACTICE TYPE } \\
\hline Private office/clinic (excluding free standing walk-in clinic) & $12(44.44)$ & $464(81.40)$ \\
\hline Community Clinic, Health Centre or Hospital & $8(29.63)$ & $89(15.61)$ \\
\hline Academic Health Sciences Centre & $7(25.93)$ & $17(2.98)$ \\
\hline \multicolumn{3}{|l|}{ PRACTICE NURSE } \\
\hline No & $8(29.63)$ & $280(49.12)$ \\
\hline Yes & $19(70.37)$ & $290(50.88)$ \\
\hline
\end{tabular}


Table 3 Patient Individual Level Characteristics $(\mathbf{n}=\mathbf{5 7 0}$ )

PREDISPOSING CHARACTERISTICS

\begin{tabular}{|c|c|c|}
\hline Demographics & Frequency (\%) & Number at BP Target (\%) \\
\hline \multicolumn{3}{|l|}{$\overline{\mathrm{AGE}}$} \\
\hline$<55$ years & $82(14.39)$ & $38(46.34)$ \\
\hline $55-64$ years & $178(31.23)$ & $107(60.11)$ \\
\hline $65-74$ years & $187(32.81)$ & $102(54.55)$ \\
\hline $75+$ years & $123(21.58)$ & $63(51.22)$ \\
\hline \multicolumn{3}{|l|}{ GENDER } \\
\hline Male & $295(51.75)$ & $163(55.25)$ \\
\hline Female & $275(48.25)$ & $147(53.45$ \\
\hline \multicolumn{3}{|l|}{ ETHNICITY } \\
\hline White & $488(85.61)$ & $265(54.30)$ \\
\hline Other & $14(2.46)$ & $9(64.29)$ \\
\hline Unknown & $68(11.93)$ & $36(52.94)$ \\
\hline \multicolumn{3}{|l|}{ Social Structure } \\
\hline \multicolumn{3}{|l|}{ EDUCATION } \\
\hline Grade 8-11 & $261(45.79)$ & $145(55.56)$ \\
\hline Completed High School & $100(17.54)$ & $49(49.00)$ \\
\hline More Education than High School & $187(32.81)$ & $101(54.01)$ \\
\hline Unknown Education & $22(3.86)$ & $15(68.18)$ \\
\hline \multicolumn{3}{|l|}{ MARITAL STATUS } \\
\hline Married/Common Law & $385(67.54)$ & $211(54.81)$ \\
\hline Single/Separated/Widowed/Divorced & $185(32.46)$ & $99(53.51)$ \\
\hline \multicolumn{3}{|l|}{ ENABLING RESOURCES } \\
\hline \multicolumn{3}{|l|}{ Personal/Family } \\
\hline \multicolumn{3}{|l|}{ PATIENT INSURANCE } \\
\hline No & $63(11.21)$ & $36(57.14)$ \\
\hline Yes & 499 (88.79) & $268(53.71)$ \\
\hline \multicolumn{3}{|l|}{ NEED } \\
\hline Evaluated Need (Clinical) & Frequency (\%) & \\
\hline \multicolumn{3}{|l|}{ YEARS SINCE HYPERTENSION DIAGNOSIS } \\
\hline In the past 5 years & $126(22.11)$ & $64(50.79)$ \\
\hline 5 to 10 years & $163(28.60)$ & $102(62.58)$ \\
\hline Over 10 years & $277(48.60)$ & $142(51.26)$ \\
\hline I do not remember & $4(0.70)$ & $2(50.00)$ \\
\hline \multicolumn{3}{|l|}{ YEARS SINCE DIABETES DIAGNOSIS } \\
\hline In the past 5 years & $164(28.77)$ & $86(52.44)$ \\
\hline 5 to 10 years & $161(28.25)$ & $98(60.87)$ \\
\hline Over 10 years & $237(41.58)$ & $122(51.48)$ \\
\hline I do not remember & $8(1.40)$ & $4(50.00)$ \\
\hline \multicolumn{3}{|l|}{ GLYCEMIC CONTROL } \\
\hline Controlled $(\mathrm{HbA} 1 \mathrm{c} \leq 7)$ & $316(56.13)$ & $177(56.01)$ \\
\hline Uncontrolled ( $\mathrm{HbA1c}>7)$ & $247(43.87)$ & $127(51.42)$ \\
\hline \multicolumn{3}{|l|}{ LIPIDS: LDL-CHOL } \\
\hline Controlled $(\mathrm{LDLC}<2.5)$ & $408(72.47)$ & $229(56.13)$ \\
\hline Uncontrolled (LDLC $\geq 2.5$ ) & $155(27.53)$ & $78(50.32)$ \\
\hline \multicolumn{3}{|l|}{ LIPIDS: HDL-CHOL } \\
\hline Controlled (Ratio TG:HDL < 4) & $373(65.67)$ & $208(55.76)$ \\
\hline Uncontrolled (Ratio TG:HDL $\geq 4$ ) & $195(34.33)$ & $101(51.79)$ \\
\hline \multicolumn{3}{|l|}{ RENAL STATUS } \\
\hline Missing & $64(11.23)$ & $24(37.50)$ \\
\hline
\end{tabular}


Table 3 Patient Individual Level Characteristics $(\mathbf{n}=\mathbf{5 7 0})$ (Continued)

\begin{tabular}{|c|c|c|}
\hline Normal & $335(58.77)$ & $198(59.10)$ \\
\hline Microalbuminuria & $83(14.56)$ & $51(61.45)$ \\
\hline Overt Nephropathy & $88(15.44)$ & $37(42.05)$ \\
\hline Perceived Need (Self-Report) & Frequency (\%) & \\
\hline BAYLISS MEAN DISEASE COUNT (SD) & $7.88(4.56)$ & \\
\hline \multicolumn{3}{|l|}{ USE OF HEALTH SERVICES } \\
\hline MEAN INTENSITY OF ANTIHYPERTENSIVE MEDICTIONS (SD) & $1.84(1.01)$ & \\
\hline \multicolumn{3}{|l|}{ Health Care System } \\
\hline \multicolumn{3}{|l|}{ DIABETES EDUCATION CLINIC ATTENDANCE (PAST YEAR) } \\
\hline Zero Visits & $386(67.72)$ & $205(53.11)$ \\
\hline One visit & $95(16.67)$ & $55(57.89)$ \\
\hline Two or More Visits & $89(15.61)$ & $50(56.18)$ \\
\hline \multicolumn{3}{|l|}{ Personal Health Practices } \\
\hline \multicolumn{3}{|l|}{ MEDICATION ADHERENCE } \\
\hline High Adherence & $404(70.88)$ & $221(54.70)$ \\
\hline Medium Adherence & $110(19.30)$ & $55(50.00)$ \\
\hline Low Adherence & $9(1.58)$ & $3(33.33)$ \\
\hline Missing & $47(8.25)$ & $31(65.96)$ \\
\hline \multicolumn{3}{|l|}{ BLOOD PRESSURE SELF-MONITORING } \\
\hline No & $224(39.30)$ & $131(58.48)$ \\
\hline Sometimes & $241(42.28)$ & $134(55.60)$ \\
\hline Often & $105(18.42)$ & $45(42.86)$ \\
\hline \multicolumn{3}{|l|}{ SMOKING } \\
\hline Current & $62(10.88)$ & $35(56.45)$ \\
\hline Past & $253(44.39)$ & $144(56.92)$ \\
\hline Never & $225(39.47)$ & $119(52.89)$ \\
\hline Unknown & $30(5.26)$ & $12(40.00)$ \\
\hline \multicolumn{3}{|l|}{ PHYSICAL ACTIVITY } \\
\hline Not able to do physical activity & $106(18.86)$ & $61(57.55)$ \\
\hline Once a week or less & $143(25.44)$ & $74(51.75)$ \\
\hline 2-3 times per week & $157(27.94)$ & $89(56.69)$ \\
\hline 4 or more times per week & $156(27.76)$ & $82(52.56)$ \\
\hline \multicolumn{3}{|l|}{ EATING FOODS LOW IN SALT } \\
\hline No & $138(24.34)$ & $63(45.65)$ \\
\hline Yes & $429(75.66)$ & $244(56.88)$ \\
\hline \multicolumn{3}{|l|}{ ALCOHOL } \\
\hline Non or Occasional Drinker & $392(68.77)$ & $210(53.57)$ \\
\hline Mild Drinker & $164(28.77)$ & $92(56.10)$ \\
\hline Heavy Drinker & $14(2.46)$ & $8(57.14)$ \\
\hline EVALUATED HEALTH STATUS & Frequency (\%) & \\
\hline \multicolumn{3}{|l|}{ OVERALL BLOOD PRESSURE AT TARGET } \\
\hline No & $260(45.61)$ & \\
\hline Yes & $310(54.39)$ & \\
\hline \multicolumn{3}{|l|}{ SYSTOLIC BLOOD PRESSURE AT TARGET } \\
\hline No & $216(37.89)$ & \\
\hline Yes & $354(62.11)$ & \\
\hline MEAN SYSTOLIC BLOOD PRESSURE (SD) & $126.06(15.51)$ & \\
\hline \multicolumn{3}{|l|}{ DIASTOLIC BLOOD PRESSURE AT TARGET } \\
\hline No & $118(20.70)$ & \\
\hline Yes & $452(79.30)$ & \\
\hline MEAN DIASTOLIC BLOOD PRESSURE (SD) & $70.96(9.94)$ & \\
\hline
\end{tabular}


Table 4 Statistically Significant Predictors for Reaching Target Blood Pressure

\begin{tabular}{|c|c|c|c|}
\hline \multirow[b]{2}{*}{ VARIABLE } & \multicolumn{3}{|c|}{ OR $(95 \% \mathrm{CL})$} \\
\hline & $\begin{array}{c}\text { BP at Target } \\
(<130 / 80 \mathrm{mmHg})\end{array}$ & $\begin{array}{l}\text { Systolic BP at Target } \\
(<130 \mathrm{mmHg})\end{array}$ & $\begin{array}{c}\text { Diastolic BP at Target } \\
(<80 \mathrm{mmHg})\end{array}$ \\
\hline \multicolumn{4}{|c|}{ INDIVIDUAL LEVEL-1 PATIENT FACTORS } \\
\hline \multicolumn{4}{|c|}{ Predisposing characteristics } \\
\hline \multicolumn{4}{|l|}{ AGE } \\
\hline$<55$ years & & - & \\
\hline $55-64$ years & & $0.93(0.54-1.60)$ & $1.87(0.88-3.89)$ \\
\hline $65-74$ years & & $0.62(0.32-1.18)$ & $3.56(1.67-7.56)^{*}$ \\
\hline $75+$ years & & $0.48(0.25-0.96)^{*}$ & $6.12(2.66-14.12)^{*}$ \\
\hline \multicolumn{4}{|l|}{ GENDER } \\
\hline Male & & & \\
\hline Female & & & $2.09(1.03-4.25)^{*}$ \\
\hline
\end{tabular}

\section{Evaluated Need}

YEARS SINCE HYPERTENSION DIAGNOSIS

In the past 5 years

5 to 10 years ago

Over 10 years ago

$1.62(1.07-2.44)^{*}$

I do not remember

$1.04(0.67-1.60)$

LIPIDS: LDL-CHOL

Uncontrolled

Controlled

$1.12(0.25-4.96)$

\begin{tabular}{|c|c|c|c|}
\hline Controlled & & & $1.68(1.14-2.49)^{*}$ \\
\hline \multicolumn{4}{|l|}{ RENAL STATUS } \\
\hline Missing & $0.52(0.28-1.01)$ & $0.45(0.23-0.87)^{*}$ & \\
\hline Normal & ---1 & 一一一一 & \\
\hline Microalbuminuria & $1.10(0.70-1.72)$ & $1.28(0.79-2.07)$ & \\
\hline Overt Nephropathy & $0.48(0.33-0.69)^{*}$ & $0.48(0.31-0.76)^{*}$ & \\
\hline \multicolumn{4}{|l|}{ Personal Health Practices } \\
\hline \multicolumn{4}{|l|}{ MEDICATION ADHERENCE } \\
\hline \multicolumn{4}{|l|}{ High Adherence } \\
\hline Medium Adherence & $0.72(0.50-1.04)$ & $0.80(0.54-1.19)$ & \\
\hline Low Adherence & $0.29(0.09-0.86)^{*}$ & $0.34(0.12-0.96)^{*}$ & \\
\hline Missing & $1.65(0.79-3.43)$ & $1.87(0.92-3.82)$ & \\
\hline \multicolumn{4}{|c|}{ BLOOD PRESSURE SELF-MONITORING } \\
\hline No & 10 & - - - & \\
\hline Sometimes & $0.87(0.58-1.30)$ & $0.79(0.53-1.18)$ & \\
\hline Often & $0.51(0.33-0.79)^{*}$ & $0.47(0.28-0.80)^{*}$ & \\
\hline \multicolumn{4}{|l|}{ EAT FOODS LOW IN SALT } \\
\hline No & & & \\
\hline Yes & $1.74(1.25-2.41)^{*}$ & & $2.35(1.49-3.70)^{*}$ \\
\hline
\end{tabular}

NOTE: Only variables found to be statistically significant in the final hierarchical models are included.

* Statistically significant

0.48; $95 \% \mathrm{CI}=0.33-0.69$ ). Eating food low in salt was associated with greater odds of reaching target $\mathrm{BP}$ (AOR = $1.74 ; 95 \% \mathrm{CI}=1.25-2.41)$. Low adherence to medication regimen (versus high) as reported on the Morisky Medication Adherence Scale was associated with lower odds of reaching target $\mathrm{BP}(\mathrm{AOR}=0.29 ; 95 \% \mathrm{CI}=0.09-0.86)$ as was the patient self-monitoring their BP (often versus no, $\mathrm{AOR}=0.51 ; 95 \%$ 0.33-0.79)

Factors significantly associated with reaching SBP target included a predisposing characteristic (age), an evaluated need factor (renal status) and personal health practices (medication adherence and BP self- 
monitoring). All were associated with lower odds of attaining SBP target. Age greater than 75 years was associated with lower odds for reaching target as were patients diagnosed with overt nephropathy, with low medication adherence and often self-monitoring their BP.

The attainment of DBP target was significantly associated with age and gender (predisposing characteristics), controlled low-density lipoprotein cholesterol (LDL-CHOL) (an evaluated need) and salt intake (a personal health practice). Female patients had twice the odds of being at DBP target as males (AOR $=2.09 ; 95 \%$ $\mathrm{CI}=1.03-4.25$ ) while patients 65 years of age and older were more than three times as likely as patients $<55$ years. Also associated with greater odds of attaining DBP target were patients with controlled LDL-CHOL $(\mathrm{AOR}=1.68 ; 95 \% \mathrm{CI}=1.14-2.49)$ and those reporting eating foods low in salt (AOR 2.35; 95\% CI 1.49-3.70).

Contextual factors pertaining to the system or providers (level 2) did not add significantly to the final multivariate models. However there was significant variability in BP at target across providers, which justified the use of the multi-level method.

\section{Discussion}

Of the 570 patients included in this analysis, $54.4 \%$ had achieved both SBP and DBP targets $(<130 / 80)$, much higher than the $27.1 \%$ reported in the baseline phase and comparable to a large study in Ontario, Canada, which also used BpTRUTM measurements (50.3\%) [7]. Two potential explanations for this might be 1) more appropriate treatment consistent with CHEP recommendations [35,36], and 2) the use of automated BP machine which reduces white coat effect $[37,38]$.

The remainder of the discussion will focus on three significant factors found by our study that potentially can be modified by interventions of health practitioners caring for hypertension. Patients who reported low medication adherence and self-monitoring of blood pressure were less likely to have achieved overall BP target levels while patients eating foods low in salt were more likely. These factors can be influenced by a wide array of health care providers.

Our results are in keeping with other studies that report an association between medication adherence and blood pressure control. In a study by Casson et al., poor adherence was associated with increases in systolic blood pressure when patients were monitored over an 18 month period [39]. Morris et al. reported that non adherent patients had higher systolic and diastolic blood pressures compared to adherent patients [40], and a metaanalysis of six studies by DiMatteo et al. showed that patients adherent to hypertensive medication had three times the odds of having better overall blood pressure control than patients who were non-adherent [41]. In the original study validating the Morisky Medication Adherence Scale, $75 \%$ of patients who reported high adherence had their BP under adequate control compared to $47 \%$ of patients who reported low adherence [31].

A review of strategies to enhance hypertensive medication adherence found that no single intervention has emerged as superior to others. It is recommended that a patient-centered approach that is tailored to overcome specific patient barriers may be the best strategy to improve adherence to hypertensive medication [42]. A variety of steps can be taken in primary care that have been shown to be effective in improving adherence: decreasing the number of daily doses [43], giving written directions and ensuring that patients understand the treatment regimen [44], home [45], or self [46] monitoring, and using medications with fewer side effects [47]. It has also been shown that pharmacist intervention can reduce SBP [48], and a recent study has reported that family physicians believe that more communication with pharmacists on the adherence issue could improve it [49]. A helpful table of strategies has been posted on the web by CHEP http://hypertension.ca/chep/therapytables/\#table 5. Further research could clarify which of these strategies is most effective in improving adherence and lowering blood pressure.

The association of self-monitoring of blood pressure with a lower likelihood of achieving BP targets contrasts with much of the literature on the topic. Bray et al. reported on a review of 25 randomized controlled trials that had been published by 2009 that included self-monitoring and self-management of blood pressure as an intervention [50]. Twelve of those studies had a cointervention with the self-monitoring; examples include patient education, contact with a health professional such as a nurse or pharmacist, phone contact, home visit, or telemetry. They concluded that self-monitoring "reduces blood pressure by a small but significant amount" [50]. Subsequently, McManus et al. demonstrated that telemonitoring and self-management (selfmonitoring plus self-titration of antihypertensive medications) were effective in controlling systolic BP [51]. Bosworth et al. conducted a randomized trial that included self-monitoring as one arm of the study. They found that self-monitoring combined with a tailored behavioral telephone intervention "improved BP control, systolic BP, and diastolic BP at 24 months relative to usual care" but the differences with self-monitoring alone were not significant [52].

Our study was an observational study, with no explicit intervention for self-monitoring. The data presented came from the patient survey response to the question "Do you check your blood pressure outside of your doctor's office?" Response options were "No," "Sometimes," 
or "Often." Those who responded "often" were less likely to be at target (overall and SBP). We have no evidence to determine how many patients were advised to self-monitor by their doctor or nurse practitioner as a component of "usual care," or how many chose to do it themselves at home or in a setting such as a pharmacy. There was no structured co-intervention. Our study design did not provide us with evidence to explain the apparent difference with previous literature. We have speculated that individuals who were not at target might be more likely to be concerned about their BP and therefore check it between office visits. It may also be that, without a co-intervention, self-monitoring alone offers a small [50] to no [52] advantage.

Our finding that patients who report a low salt diet are more likely to be at overall target and diastolic BPs comes as no surprise and gives support to current guidelines [27]. It strongly suggests where health care providers could focus their attention when dealing with patients whose pressures are still higher than desired. Discussion of salt restriction, on an equal footing with the medications they must take, will emphasize to the patient the importance of this restriction. A verbal "prescription" to specifically decrease salt can accompany written prescriptions for medications. A referral to, and conversation with, a nutritionist or diabetes educator regarding counseling on diet and sodium reduction, could ensure that this is treated as a high priority by the patient.

Our "real world" community practice setting, in rural and urban locations with a variety of available resources and supports for patients, is a strength of this study. A small number of academic practices (10) contributed only $8 \%$ of the patient cohort. None of the practices had a special focus on diabetes; all were broad primary care practices of physicians and nurse practitioners interested in contributing to research. As well, our high patient survey response rate $(89.6 \%)$ reinforces the value of our data and enhances the generalizability of our findings. An additional strength is the use of hierarchical nonlinear modeling which allowed us to control for the clustering of patients within practices and the variance between providers.

One of the limitations of our study is that the population is less ethnically diverse than the general Canadian population. Some measures were derived from a selfreported mailed survey and may be subject to over- or under-reporting. However, commonly biased self-report measures (such as age, weight, and smoking status) all came from the provider, not the patient. Additionally, $8 \%$ of the data for medication adherence was missing. Only patients with an available BpTRUTM measurement were included in analysis and because of this, a small number of patients could not be included. Their providers could not obtain a BPTRUTM reading due to the size and shape of the arm. These were very high BMI patients with a "conically" shaped arm.

\section{Conclusions}

Although numerous factors have been shown to be associated with achieving BP targets, our study identified two specific issues that health practitioners should focus on when treating patients who are still not at target. They should emphasize salt-restriction, possibly with referral to a nutritionist, and employ patient-centered strategies to assess and enhance medication adherence.

\section{Acknowledgements and Funding}

The authors wish to thank Dr. Paul Veugelers for his advice regarding hierarchical non-linear modeling, and Ms. Charmaine Cooke for her assistance with drug analysis. Dr. Preston Smith and Dr. Michael Murray contributed to the development of our project and to the recruitment of patients from their private practices. We also wish to thank all of the participating family physicians and nurse practitioners who recruited patients for this study, and the patients themselves for their willingness to be involved and to complete our mail survey.

The operating funding for this phase of our project was provided by the Canadian Institutes of Health Research ROP-82512, the Nova Scotia Health Research Foundation, and the Heart \& Stroke Foundation of Nova Scotia. The BPTRUTM equipment used in this study was funded by the Office of Research Services of the Faculty of Medicine Dalhousie University, and the Capital District Health Authority of Halifax, Nova Scotia. The earlier phase of our study, which was essential to the main report, was also supported by the Dalhousie Medical Research Foundation, and the Prince Edward Island Health Research Institute.

Ingrid Sketris holds a Canadian Health Services Research Foundation/ Canadian Institutes of Health Research Chair in Health Services Research, cosponsored by the Nova Scotia Health Research Foundation.

\section{Author details}

${ }^{1}$ Department of Family Medicine, Dalhousie University, Oxford St., Halifax, NS, B3H 4R2, Canada. ${ }^{2}$ Community-based physician. ${ }^{3}$ College of Pharmacy, Dalhousie University, Oxford St., Halifax, NS, B3H 4R2, Canada. ${ }^{4}$ Department of Medicine, Dalhousie University, Oxford St., Halifax, NS, B3H 4R2, Canada. ${ }^{5}$ Diabetes Care Program of Nova Scotia, South Park St., Halifax, NS, B3H 2Y9, Canada. ${ }^{6}$ Discipline of Family Medicine, Memorial University of Newfoundland, PO Box 4200, St. John's, NL, A1C 5S7, Canada.

\section{Authors' contributions}

WP and BL participated in the conception and design of this study, the analysis and interpretation of results, and drafting and revising the manuscript. $\mathrm{FB}, \mathrm{MG}, \mathrm{RAG}, \mathrm{JH}, \mathrm{KL}$, and $\mathrm{IM}$ participated in the conception and design of the study, acquisition of data, the interpretation of results, and the revising of the manuscript for intellectual content. FIB, NN, IS, BM, PD took part in the conception and design of the study, the interpretation of the results, and the revising of manuscript for intellectual concept. KVA took part in the analysis and interpretation of the results and the drafting and revising of the manuscript. MSG participated in the interpretation of the results and the revising of the manuscript. All authors have approved the final version.

\section{Competing interests}

The authors declare that they have no competing interests.

Received: 4 February 2011 Accepted: 11 August 2011

Published: 11 August 2011

\section{References}

1. Report from the National Diabetes Surveillance System: Diabetes in Canada, 2009. National Diabetes Surveillance System, editor; 2009, 1-5. 
2. Putnam W, Buhariwalla F, Lacey K, Goodfellow M, Goodine RA, Hall J, MacDonald I, Murray M, Smith P, Burge F, Natarajan N, Lawson B: Drug management for hypertension in type 2 diabetes in family practice. Can Fam Physician 2009, 55:728-734.

3. Harris SB, Ekoé J, Zdanowicz Y, Webster-Bogaert S: Glycemic control and morbidity in the Canadian primary care setting (results of the diabetes in Canada evaluation study). Diabetes Res Clin Pract 2005, 70:90-97.

4. Supina AL, Guirguis LM, Majumdar SR, Lewanczuk RZ, Lee TK, Toth EL, Johnson JA: Treatment gaps for hypertension management in rural Canadian patients with type 2 diabetes mellitus. Clin Ther 2004 26(4):598-606.

5. American Diabetes Association: Treatment of hypertension in adults with diabetes. Diabetes Care 2002, 25(1):199-201.

6. Basile JN, Lackland DT, Basile JM, Riehle JE, Egan BM: A statewide primary care approach to cardiovascular risk factor control in high-risk diabetic and nondiabetic patients with hypertension. J Clin Hypertens 2004, 6(1):18-25.

7. Leenen FHH, Dumais J, Mclnnis NH, Turton P, Stratychuk L, Nemeth K, LumKwong MM, Fodor G: Results of the Ontario Survey on the Prevalence and Control of Hypertension. Can Med Assoc J 2008, 178(11):1441-1449.

8. Houlihan SJ, Simpson SH, Cave AJ, Flook NW, Hurlburt ME, Lord CJ, Smith LL, Sternberg HH: Hypertension treatment and control rates: Chart review in an academic family medicine clinic. Can Fam Physician 2009, 55:735-742.

9. Nelson SA, Dresser GK, Feldman RD: Determinants of poor blood pressure control in hypertensive patients with diabetes: A STITCH substudy [abstract \#51]. Can J Cardiol 2009, 25(SupplSB).

10. McCrate F, Godwin M, Murphy L: Attainment of Canadian Diabetes Association recommended targets in patients with type 2 diabetes. Can Fam Physician 2010, 56:13-19.

11. Hänninen JA, Takala JK, Keinänen-Kiukaanniemi SM: Blood pressure control in subjects with type 2 diabetes. J Hum Hypertens 2000, 14:111-115.

12. Pellegrini F, Belfiglio M, De Berardis G, Franciosi M, Di Nardo B, Greenfield S, Kaplan SH, Sacco M, Tognoni G, Valentini M, Corrado D, D'Ettorre A, Nicolucci A: Role of organizational factors in poor blood pressure control in patients with type 2 diabetes. Arch Intern Med 2003, 163:473-480.

13. Ornstein SM, Nietert PJ, Dickerson LM: Hypertension management and control in primary care: A study of 20 practices in 14 states. Pharmacotherapy 2004, 24(4):500-507.

14. Schaars CF, Denig P, Kasje WN, Stewart RE, Wolffenbuttel BH, HaaijerRuskamp FM: Physician, organizational, and patient factors associated with suboptimal blood pressure management in type 2 diabetic patients in primary care. Diabetes Care 2004, 27(1):123-128.

15. Sequeira RP, Al Khaja KA, Damanhori AH: Evaluating the treatment of hypertension in diabetes mellitus: A need for better control? J Eval Clin Pract 2004, 10(1):107-116.

16. Hyman DJ, Pavlik VN: Characteristics of patients with uncontrolled hypertension in the United States. N Engl J Med 2001, 345(7):479-486.

17. Spann SJ, Nutting PA, Galliher JM, Peterson KA, Pavlik VN, Dickinson LM, Volk RJ: Management of type 2 diabetes in the primary care setting: A practice-based research network study. Ann Fam Med 2006, 4(1):23-31.

18. McFarlane SI, Castro J, Kaur J, Shin JJ, Kelling D, Farag A, Simon N, El-Atat F, Sacerdote A, Basta E, Flack J, Bakris G, Sowers JR: Control of blood pressure and other cardiovascular risk factors at different practice settings: Outcomes of care provided to diabetic women compared to men. J Clin Hypertens 2005, 7(2):73-80.

19. Lloyd-Jones DM, Evans JC, Levy D: Hypertension in adults across the age spectrum: current outcomes and control in the community. JAMA 2005, 294(4):466-472.

20. Kotchen JM, Shakoor-Abdullah B, Walker WE, Chelius TH, Hoffmann RG, Kotchen TA: Hypertension control and access to medical care in the inner city. Am J Public Health 1998, 88(11):696-699.

21. Brown JB, Harris SB, Webster-Bogaert S, Wetmore S, Faulds C, Stewart M: The role of patient, physician and systemic factors in the management of type 2 diabetes mellitus. Fam Pract 2002, 19(4):344-349.

22. Berlowitz DR, Ash AS, Hickey EC, Glickman M, Friedman R, Kader B: Hypertension management in patients with diabetes: The need for more aggressive therapy. Diabetes Care 2003, 26(2):355-359.

23. Hicks LS, Fairchild DG, Horng MS, Orav EJ, Bates DW, Ayanian JZ: Determinants of JNC VI guideline adherence, intensity of drug therapy, and blood pressure control by race and ethnicity. Hypertension 2004, 44(4):429-434.

24. Andersen RM: Revisiting the behavioral model and access to medical care: does it matter? J Health Soc Behav 1995, 36(1):1-10.

25. Canadian Diabetes Association Clinical Practice Guidelines Expert Committee: Canadian Diabetes Association 2003 clinical practice guidelines for the prevention and management of diabetes in Canada. Can J Diabetes 2003, 27.

26. Khan NA, MCAlister FA, Rabkin SW, Padwal R, Feldman RD, Campbell NRC, Leiter LA: The 2006 Canadian Hypertension Education Program recommendations for the management of hypertension: Part II Therapy. Can J Cardiol 2006, 22(7):583-593.

27. Khan NA, Hemmelgarn B, Herman RJ, Bell CM, Mahon JL, Leiter LA, Rabkin SW: The 2009 Canadian Hypertension Education Program recommendations for the management of hypertension: Part 2 therapy. Can J Cardiol 2009, 25(5):287-298.

28. Ménard J, Payette H, Baillargeon J, Maheux P, Lepage S, Tessier D, Ardilouze J: Efficacy of intensive multitherapy for patients with type 2 diabetes mellitus: a randomized controlled trial. Can Med Assoc J 2005, 173(12).

29. Compendium of pharmaceuticals and specialties (CPS) Ottawa (ON): Canadian Pharmacists Association; 2006.

30. Salant P, Dillman DA: How to conduct your own survey Toronto (ON): John Wiley \& Sons, Inc; 1994

31. Morisky DE, Green LW, Levine DM: Concurrent and predictive validity of a self-reported measure of medication adherence. Med Care 1986, 24(1):67-74.

32. Bayliss EA, Ellis JL, Steiner JF: Subjective assessments of comorbidity correlate with quality of life health outcomes: Initial validation of a comorbidity assessment instrument. Health Qual Life Outcomes 2005, 3:51.

33. Raudenbush SW, Bryk AS, Cheong YKea: Hierarchical Linear and Nonlinear Modeling. Lincolnwood, IL, HLM 6.08 for Windows Scientific Software International, Inc; 2004

34. SAS/STAT Cary (NC): SAS Institute Inc. 2003

35. Campbell NRC, Tu K, Brant R, Duong-Hua M, McAlister FA: The impact of the Canadian Hypertension Education Program on antihypertensive prescribing trends. Hypertension 2006, 47:22-28.

36. Hemmelgarn BR, Chen G, Walker R, McAlister FA, Quan H, Tu K, Khan N, Campbell N: Trends in antihypertensive drug prescriptions and physician visits in Canada between 1996 and 2006. Can J Cardiol 2008, 24(6):507-512.

37. Myers MG: Automated blood pressure measurement in routine clinical practice. Blood Press Monit 2006, 11(2):59-62.

38. Myers $M G$, Valdivieso MA: Use of an automated blood pressure recording device, the BpTRU, to reduce the "white coat effect" in routine practice. Am J Hypertens 2003, 16(6):494-497.

39. Casson Rl, King WD, Godwin NM: Markers of loss of control of hypertension. Can Fam Physician 2003, 49:1323-1331.

40. Morris AB, Li J, Kroenke K, Bruner-England TE, Young JM, Murray MD: Factors associated with drug adherence and blood pressure control in patients with hypertension. Pharmacotherapy 2006, 26(4):483-492.

41. DiMatteo MR, Giordani PJ, Lepper HS, Croghan TW: Patient adherence and medical treatment outcomes: a meta-analysis. Med Care 2002, 40(9):794-811.

42. Krousel-Wood M, Hyre A, Muntner P, Morisky D: Methods to improve medication adherence in patients with hypertension: current status and future directions. Curr Opin Cardiol 2005, 20(4):296-300.

43. Schroeder K, Fahey T, Ebrahim S: Interventions for improving adherence to treatment in patients with high blood pressure in ambulatory settings. Cochrane Database of Systematic Reviews 2004, , 3: 1-31.

44. Bosworth HB, Olsen MK, Oddone EZ: Improving blood pressure control by tailored feedback to patients and clinicians. Am Heart J 2005, 149:795-803.

45. Cappuccio FP, Kerry SM, Forbes L, Donald A: Blood pressure control by home monitoring: meta-analysis of randomised trials. BMJ 2004

46. Glynn LG, Schroeder K, Fahey T: Interventions used to improve control of blood pressure in patients with hypertension. Cochrane Database of Systematic Reviews 2010, 3: 1-3.

47. Elliott WJ: Improving Outcomes in Hypertensive Patients: Focus on Adherence and Persistence With Antihypertensive Therapy. J Clin Hypertens 2009, 11:376-382 
48. Machado M, Bajcar J, Guzzo GC, Einarson TR: Sensitivity of Patient Outcomes to Pharmacist Interventions. Part II: Systematic Review and Meta-Analysis in Hypertension Management. Ann Pharmacother 2007, 41:1770-1781.

49. Laubscher T, Evans C, Blackburn D, Taylor J, McKay S: Collaboration between family physicians and community pharmacists to enhance adherence to chronic medications. Can Fam Physician 2009, 55:69-75.

50. Bray EP, Holder R, Mant J, McManus RJ: Does self-monitoring reduce blood pressure? Meta-analysis with meta-regression of randomized controlled trials. Ann Med 2010, 42(5):371-386.

51. McManus RJ, Mant J, Bray EP, Holder R, Jones MI, Greenfield S, Kaambwa B, Banting M, Bryan S, Little P, Williams B, Hobbs FD: Telemonitoring and selfmanagement in the control of hypertension (TASMINH2): a randomised controlled trial. Lancet 2010, 376(9736):163-172.

52. Bosworth HB, Olsen MK, Grubber JM, Neary AM, Orr MM, Powers BJ, Adams MB, Svetkey LP, Reed SD, Li Y, Dolor RJ, Oddone EZ: Two selfmanagement interventions to improve hypertension control: a randomized trial. Ann Intern Med 2009, 151(10):687-695.

\section{Pre-publication history}

The pre-publication history for this paper can be accessed here: http://www.biomedcentral.com/1471-2296/12/86/prepub

doi:10.1186/1471-2296-12-86

Cite this article as: Putnam et al.: Hypertension and type 2 diabetes: What family physicians can do to improve control of blood pressure an observational study. BMC Family Practice 2011 12:86.

\section{Submit your next manuscript to BioMed Central and take full advantage of:}

- Convenient online submission

- Thorough peer review

- No space constraints or color figure charges

- Immediate publication on acceptance

- Inclusion in PubMed, CAS, Scopus and Google Scholar

- Research which is freely available for redistribution

Submit your manuscript at www.biomedcentral.com/submit 